\title{
Gangliogenesis in Leech Embryos: Migration of Neural Precursor Cells
}

\author{
Steven A. Torrence and Duncan K. Stuart \\ Department of Molecular Biology, University of California, Berkeley, Berkeley, California 94720
}

In the metameric CNS of leeches, identified neurons occupy highly stereotyped positions in each segmental ganglion. Although many of the neural precursor cells arise near their definitive positions, some arise outside the prospective domain of the segmental ganglia and thus must migrate into the CNS. Here, we report the results of an analysis of the role of cell migration in gangliogenesis in the leech Theromyzon rude. Segmental ganglia of the ventral nerve cord arise as laterally thickened sheets of tissue lying astride the ventral midline. Particular identified circular and longitudinal muscle fibers, visualized by indirect immunofiuorescence using a monoclonal antibody against leech muscle, outline the presumptive ganglionic territories even before the ganglionic rudiments become morphologically distinct and serve as anatomical landmarks to which the cell movements are related. Cell lineage tracers microinjected into precursor blastomeres are used to visualize migratory cells. Small groups of neural precursor cells that arise outside the prospective ganglionic territories migrate with stereotyped timing along stereotyped pathways to reach their definitive positions, and each group of migratory cells gives rise to a stereotyped subset of the cells in a ganglion. No segmental or regional differences are observed in any aspect of cell migration studied here, supporting the view that segmental differences in the architecture of the leech CNS arise only after the initial condensation of the ganglionic rudiments.

The highly stereotyped CNS of the leech consists of an anterior, presegmental supraesophageal ganglion and a ventral nerve cord comprising a chain of 32 segmental ganglia interlinked via longitudinal connective nerves (Mann, 1962; Muller et al., 1981). To a first approximation the segmental ganglia are anatomically alike and contain homologous complements of cells, although there are regional divergences from the basic pattern. Many of the approximately 400 serially homologous neurons in each segmental ganglion (Macagno, 1980) have been individually identified (Muller et al., 1981). From ganglion to ganglion and leech to leech, each identified neuron has a characteristic position, morphology, projection pattern, and physiological function.

The PNS of the leech is similarly stereotyped, although less well characterized. It consists of a bilaterally symmetrical and segmentally iterated system of 4 major circumferential nerve trunks and their branches, which contain both the centrifugal

\footnotetext{
Received Jan. 13, 1986; revised Mar. 14, 1986; accepted Mar. 17, 1986.

This work was supported in part by NIH NRSA NS07212 and by research grants NS 12818 and HD 17088 from the NIH and BNS 79-12400 from the National Science Foundation, as well as by grants from the March of Dimes Birth Defects Foundation and the Rowland Foundation. We thank Professor Gunther Stent for his helpful comments on this manuscript.

Correspondence should be addressed to Steven A. Torrence, Department of Molecular Biology, Stanley Hall, University of California, Berkeley, Berkeley, CA 94720.

Copyright (c) 1986 Society for Neuroscience $0270-6474 / 86 / 092736-11 \$ 02.00 / 0$
}

axons of neurons situated in the CNS and the centripetal axons of neurons situated in the periphery. Some of the peripheral neurons have been identified (Blackshaw et al., 1982; Blair, 1983; Braun, 1985; Rude, 1969; Stuart et al., 1986; Weisblat and Shankland, 1985).

The development of the leech nervous system is as stereotyped as its adult architecture. The sequence of embryonic cell divisions is highly determinate, and developmental cell lineage analyses in the glossiphoniid leeches Helobdella triserialis and Haementeria ghilianii have shown that each of the major ectodermal and mesodermal precursor blastomeres contributes a stereotyped subset of the cells in each segmental ganglion, as wcll as in the periphery of each segment (Kramer and Weisblat, 1985; Weisblat et al., 1978, 1980a, 1984).

Although the pattern of cell divisions in leech embryogenesis causes many cells to arise near the sites of their ultimate differentiation (Stent, 1985; Stent et al., in press), some precursors of neurons and glia of the CNS do arisc outside the prospective domain of the ventral nerve cord and must migrate centripetally to enter the CNS (Weisblat et al., 1984). By "migration" we mean that cells abandon one set of cellular neighbors and move through adjacent tissues to a destination where they acquire another set of cellular neighbors.

This report presents the results of a study of the role of cell migration in the development of the CNS of the glossiphoniid leech Theromyzon rude, using cell lineage tracer techniques. We show that small groups of neural precursor cells that arise outside the prospective domain of the ventral nerve cord migrate centripetally along stereotyped pathways and with stereotyped timing to reach their definitive locations in and near the segmental ganglia. For this purpose, we refer to the gridlike pattern of differentiating body-wall muscle fibers, which provide anatomical landmarks to which the observed cellular movements are related. These results are likely to apply to $H$. triserialis and $H$. ghilianii as well as to $T$. rude, since we find that the developmental cell lineage patterns of the 4 major ectodermal cell lines in $T$. rude, which had not previously been described, are nearly identical to the patterns previously described in the other two glossiphoniid species.

\section{Summary of Development}

The embryonic development of $T$. rude is similar to that of other glossiphoniid species (Fernandez, 1980; Fernandez and Olea, 1982; Fernandez and Stent, 1980; Stent et al., 1982, in press; Weisblat, 1981). Among the progeny of the determinate, asymmetrical early cleavages are 5 bilateral pairs of large cells called teloblasts, of which 4 pairs are the precursors of the definitive ectoderm and the 5th pair is the precursor of the mesoderm. During embryonic stage 7, each teloblast buds off a series of several dozen smaller primary blast cells, which form a longitudinal row, or bandlet. The 4 ectodermal precursor bandlets on each side of the embryo are designated $n, o, p$ and $q$, and the mesodermal precursor bandlet on each side is designated 
m. Within each bandlet, the firstborn and developmentally oldest blast cells are located at the anterior end, and their mitotic progeny will contribute to the anteriormost segments of the body. Progressively younger blast cells are located progressively more posteriorly in the bandlet and will contribute their progeny to correspondingly more posterior segments. In accord with this anterior-to-posterior gradient of decreasing blast cell age, any given developmental event occurs first in the anteriormost segments and progressively later in progressively more posterior segments. Each embryo thus provides an orderly and finely graded series of developmental substages, in which the embryo's longitudinal axis is equivalent to a developmental time axis from which sequential developmental events may be inferred.

A complex series of morphogenetic movements of the 5 bilateral pairs of bandlets during stage 8 results in their coalescence along the future ventral midline to form the primordium of the body wall and nervous system: the germinal plate. During stage 9 the primordia of the organs of the body wall and nervous system, including the segmental ganglia of the ventral nerve cord, appear in the germinal plate, and it is during this stage that the cell migrations to be described in this paper take place. During stage 10 the germinal plate expands circumferentially to cover the entire surface of the embryo and enclose the tubular body of the leech.

\section{Materials and Methods \\ Specimens}

Gravid specimens of $T$. rude were collected from the lakes of Golden Gate Park, San Francisco, California, and maintained at $12-14^{\circ} \mathrm{C}$ in small glass bowls in a dilute solution of Instant Ocean artificial sea salts $(0.38 \mathrm{gm} /$ liter $)$. Each gravid leech produces a clutch of 50-150 eggs, deposited in a cluster of 2-7 egg cases attached to the glass of the bowl.

Embryos were removed from their egg cases and cultured at 18 or $12^{\circ} \mathrm{C}$ in a medium containing $4.8 \mathrm{mM} \mathrm{NaCl}, 1.2 \mathrm{~mm} \mathrm{KCl}, 2.0 \mathrm{~mm} \mathrm{MgCl}_{2}$, $8.0 \mathrm{mM} \mathrm{CaCl}_{2}$, and $1.0 \mathrm{~mm}$ maleic acid, adjusted to $\mathrm{pH} 6.6$ (Weisblat et al., 1980a). The embryonic staging system used here is that of Fernandez (1980), as reviscd by Wcisblat ct al. (1980a).

We follow the convention whereby a segment is defined as the anatomical unit associated with one of the individual ganglia of the (embryonic) ventral nerve cord (Mann, 1953; Weisblat and Shankland, 1985). Body segments are numbered consecutively, I-XXXII, anterior to posterior (Mann, 1962), without regard to regional specializations of the nerve cord. The traditional Roman numerals are used to distinguish this enumeration system from the system using Arabic numerals, which numbers only "abdominal" segments containing discrete, unfused segmental ganglia. Abdominal ganglion 1 according to the latter system lies in segment $\mathrm{V}$ according to the system used here.

\section{Cell lineage tracing}

Early embryonic blastomeres were injected with fluorescent cell lineage tracer molecules as described previously for embryos of $\boldsymbol{H}$. triserialis (Weisblat et al., 1980b). The embryos were then allowed to develop to appropriate stages and fixed as described below. Injection solutions consisted of $75 \mathrm{mg} / \mathrm{ml}$ tetramethylrhodamine-dextran-amine (RDA) or fluorescein-dextran-amine (FDA) (Gimlich and Braun, 1985) and 10 $\mathrm{mg} / \mathrm{ml}$ Fast green dissolved in $200 \mathrm{~mm} \mathrm{KCl}$.

\section{Fixation and dissection}

Embryos labeled with fluorescent lineage tracers and embryos to be stained by indirect immunofluorescence (see below) were fixed overnight at $4^{\circ} \mathrm{C}$ in $2.8 \%$ formalin in $50 \mathrm{~mm}$ HEPES buffer, pH 7.4, supplemented with $5 \mu \mathrm{g} / \mathrm{ml}$ of the DNA-specific, fluorescent dye Hoechst 33258 (Calbiochem or Aldrich). After fixation the embryos were rinsed in a buffered saline (HBS) containing $50 \mathrm{~mm}$ HEPES, $145 \mathrm{~mm} \mathrm{NaCl}$, and $15 \mathrm{~mm}$ $\mathrm{NaN}_{3}$, pH 7.4. Embryos immersed in HBS were pinned out on Sylgard, and a longitudinal incision was made along the dorsal midline to allow the central mass of yolk to be teased out.

\section{Indirect immunofluorescence labeling}

Embryonic muscle fibers were stained by indirect immunofluorescence using a mouse monoclonal antibody directed against leech muscle (Lan
3-14; Zipser and McKay, 1981), which was generously provided to us by Dr. B. Zipser. Fixed and dissected embryos were incubated overnight in HBS containing Lan 3-14 ascites fluid (1:1000), 2\% Triton X-100, and $1 \%$ wholc goat scrum (Cappcl), then rinscd in HBS containing $2 \%$ Triton X-100 and 3\% goat serum, and stained overnight in HBS containing fluorescein-conjugated goat anti-mouse serum (GAM, Cappel, 1:200) or rhodamine-conjugated GAM (Cappel, 1:400), 2\% Triton X-100, and $3 \%$ goat serum. After staining, the preparations were rinsed several times, first in HBS with $2 \%$ Triton X-100 and 3\% goat serum, then in HBS alone, before being mounted for observation. All steps were performed at $4^{\circ} \mathrm{C}$.

\section{Microscopy}

\section{Whole mounts}

Dissected embryos labeled with fluorescent cell lineage tracers or stained by indirect immunofluorescence were cleared and mounted flat between coverslips in a mixture composed of $80 \%$ glycerol and $20 \% 100 \mathrm{~mm}$ TRIS-HCl buffer, $\mathrm{pH} 9$, with $40 \mathrm{mg} / \mathrm{ml} n$-propyl gallate added to retard photobleaching of the fluorophores (Giloh and Sedat, 1982).

The embryos were examined by epifluorescence microscopy, using Zeiss filter set 487715 to visualize RDA, filter set 487717 to visualize FDA, and filter set 487702 to visualize Hoechst 33258, and were photographed on Kodak Ektachrome 160 Professional or Ektachrome 400 film to obtain color transparencies. Micrographs showing 2 different labels in the same specimen (Figs. $4 B, D ; 7 A ; 8$ ) were made as double exposures, using first the filter set appropriate for one of the labels, then the filter set appropriate for the other label. Micrographs were printed from the color transparencies onto Kodak Panalure panchromatic enlarging paper; in the resulting negative images, fluorescence is rendered dark against a light background (Figs. 4, 6-8).

\section{Sections}

Embryos were fixed for $2.5 \mathrm{hr}$, on ice, in half-strength Karnovsky's (1965) fixative (final concentrations: $2 \%$ paraformaldehyde, $2.5 \%$ glutaraldehyde, $1 \mathrm{~mm} \mathrm{CaCl}$, and $50 \mathrm{~mm}$ sodium cacodylate buffer, $\mathrm{pH}$ 7.4), rinsed briefly in the following secondary fixative, postfixed for 1 $\mathrm{hr}$, on ice, in $1 \% \mathrm{OsO}_{4}$ in $50 \mathrm{~mm}$ sodium cacodylate buffer, $\mathrm{pH} 7.4$, dehydrated in isopropanol (Torrence and Cloney, 1981), cleared in propylcnc oxide, and cmbedded in EMBED 812 (EMS). Onc micrometer sections were cut on glass knives, stained with an aqueous solution of $5 \mathrm{mg} / \mathrm{ml}$ methylene blue, $5 \mathrm{mg} / \mathrm{ml}$ toluidine blue, and $5 \mathrm{mg} / \mathrm{ml}$ sodium borate, and photographed on Kodak Technical Pan Film 2415 with a green interference filter to enhance sharpness and contrast.

\section{Results}

\section{Organization of the germinal plate}

\section{Early germinal plate}

Early in stage 9 , before cell migration has begun, the germinal plate is a strip of tissue about $250-300 \mu \mathrm{m}$ wide and $30-40 \mu \mathrm{m}$ thick, extending longitudinally over the ventral surface of the embryo (Fig. 1). Within the newly coalesced germinal plate, the 4 pairs of ectodermal bandlets lie in a single layer, and on either side of the ventral midline they are arranged in the mediolateral order $\mathrm{n}, \mathrm{o}, \mathrm{p}, \mathrm{q}$ (Figs. $1 B, 2$ ). Thus, the right and left $\mathrm{n}$ bandlets are in contact with one another along the ventral midline, and the $\mathrm{q}$ bandlets lie at the lateral margins of the germinal plate. There is as yet no coherent or morphologically recognizable ganglionic rudiment (Figs. 1, 2). The right and left $\mathrm{m}$ bandlets lie deep to the ectodermal bandlets and are also in contact with one another along the ventral midline (Figs. $1 B, 2$ ). No coelomic cavity is yet manifest.

The germinal plate is bilaterally symmetrical; in the following, we will describe the development of only one side (i.e., one hemiplate). It should be understood that all events and structures reported here have mirror-symmetrical counterparts in the opposite hemiplate.

\section{Late germinal plate}

By the end of stage 9, the germinal plate has undergone extensive rearrangements, among them the migrations to be described 

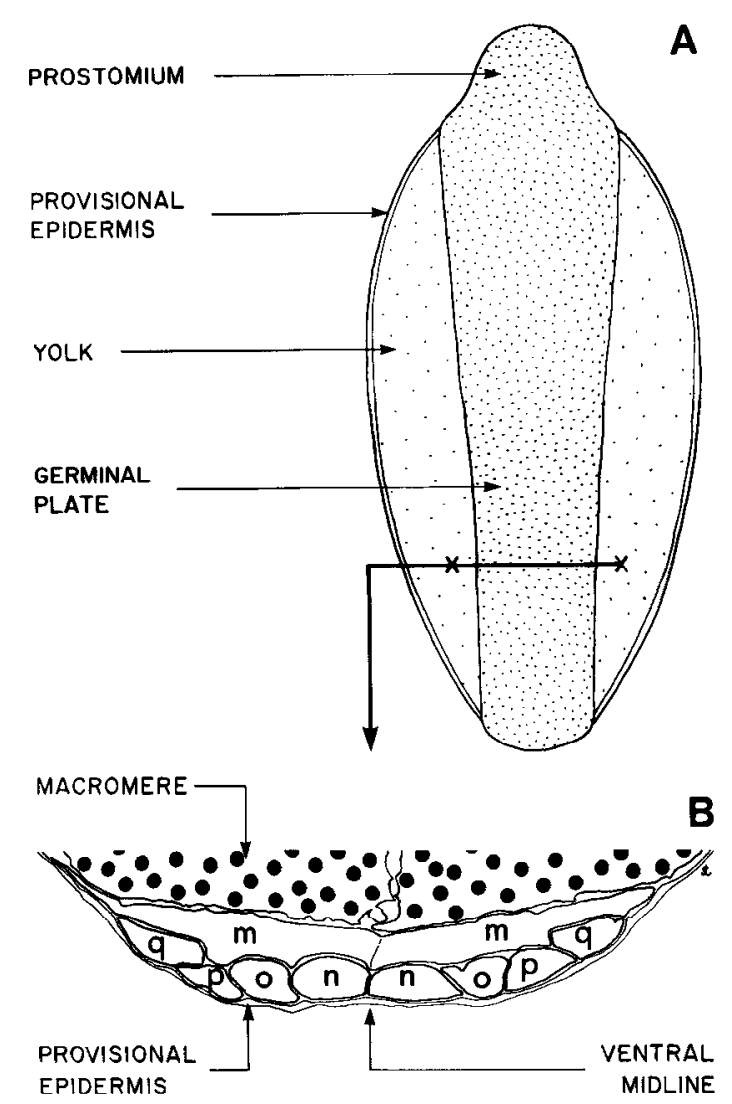

Figure 1. Diagrams showing the anatomy of the germinal plate of Theromyzon rude. A, Vicw of the ventral surface of an carly stage? embryo. Anterior is uppermost. The germinal plate (dense stippling) extends longitudinally over the ventral surface on either side of the midline. The interior of the embryo is occupied by large yolky cells, the macromeres, and the surface is covered by the provisional epidermis. $B$, Diagrammatic transverse section along the line $\mathrm{X}-\mathrm{X}$ in $A$, representing a section similar to that shown in Figure 2 and showing the positions of the 8 ectodermal (right and left: $n, o, p$, and $q$ ) and 2 mesodermal (right and left: $m$ ) bandlets. Because of cellular proliferation, bandlets are more than 1 cell wide in transverse section; thus, the bandlet contours drawn here encompass more than 1 cell each ( $c f$. Fig. 2). The large dots in the macromeres symbolize yolk granules.

below, and the major organs and tissues of the body wall and nervous system are differentiating in approximately their definitive anatomical interrelationships. The segmental ganglia have formed along the ventral midline (Fig. 3), between the bodywall muscles and the epithelial lining of the coelom. The 3 segmental nerve roots of each hemiganglion have been established and give rise to the major circumferential segmental nerves in the body wall: the anteroanterior (AA; Fig. 6), medioanterior (MA; Figs. 3, 6), and posteroposterior (PP; Fig. 6) nerves, and to the deep-lying dorsoposterior (DP) nerve in the segmental septum. Peripheral neurons have appeared at characteristic locations along the segmental nerves (Figs. 5, 6B).

Although the germinal plate has increased somewhat in width from the beginning of stage 9 , it is still a flat strip along the ventral aspect of the embryo, with structures at its lateral margins that are ultimately destined to lie along the dorsal midline. (It should be noted that "medial" and "lateral" are used in this paper to refer to stage 9 embryonic anatomical axes; the lateral parts of the germinal plate, which are destined to form the dorsal body wall of the juvenile leech, become reoriented during stage 10.) As the germinal plate expands during stage 10 , distances between organs increase, but topographical relationships established in stage 9 are largely preserved.

\section{Body-wall muscles as anatomical landmarks}

Following the migrations of neural precursors into the ganglionic rudiments requires anatomical landmarks to which the cellular movements can be related. Such landmarks are provided by the pattern of differentiating circular and longitudinal muscle fibers of the body wall. In each hemisegment of the early germinal plate, individual, identified muscle fibers differentiate in a stereotyped order and in stereotyped positions (Stuart et al., 1982; D. K. Stuart, unpublished observations). Only a few prominent, early muscle fibers are discussed here; the complete pattern of muscle fiber differentiation will be describcd clsewhere.

The first circular muscle fiber to differentiate in each hemisegment, designated the "primary circular" fiber (Figs. $4 B, D$; $7 A ; 8$ ), spans the entire distance from the ventral midline to the lateral margin of the germinal plate. This fiber marks the position of the future cleft between adjacent ganglia and defines the anterior edge of the segment.

Among the earliest longitudinal muscles to differentiate is a prominent band of fibers that lie deeper in the germinal plate (i.e., further from the epidermis) than other longitudinal fibers of the body-wall musculature. These will be referred to as the "deep longitudinal" fibers (Figs. $4 B, D ; 7 A ; 8$ ), although later in development they will come to lie at the same depth as the rest of the longitudinal muscles.

The primary circular and deep longitudinal muscle fibers become visualizable by indirect immunofluorescence before the ganglia become morphologically distinct (Fig. 4, C, D). When the nascent segmental ganglia do become morphologically distinct, each occupies the rectangular space bounded by 2 successive primary circular fibers and the right and left deep longitudinal fibers (Fig. 4). Thus, these muscle fibers outline the presumptive ganglionic territory in each segment, within which the neural precursors of the ganglionic rudiment are to condense.

\section{Gangliogenesis}

At the beginning of gangliogenesis, the presumptive ganglionic territory, outlined by the primary circular and deep longitudinal muscle fibers, is occupied by a flat sheet of cells, which, when observed in whole mount, is not visibly distinct from the surrounding tissues (Fig. $4, C, D$ ). As cells accumulate within this territory by proliferation and centripetal migration, the lateral parts of the nascent ganglion thicken. These segmentally iterated thickenings correspond to the bilaterally paired hemiganglionic primordia that have been described previously (Fernandez, 1980; Kuwada and Kramer, 1983). However, it should be noted that presumptive neural tissue is also present in the medial region between the lateral thickenings; the sheet of tissue is merely thinner there. The entire sheet of tissue that occupies the presumptive ganglionic territory of a single segment is referred to here as a ganglionic rudiment to distinguish it from the paired thickenings that were previously designated "ganglionic primordia."

As gangliogenesis proceeds, notches appear in the lateral margins of the sheet of presumptive neural tissue, where it overlies the primary circular muscle fibers that mark the anterior and posterior margins of the presumptive ganglionic territory. These notches between longitudinally adjacent thickenings are the incipient interganglionic clefts (Fig. 4). Adjacent ganglia remain in contact until near the end of stage 9 , when they begin to move apart from one another, linked via the lengthening longitudinal nerve fiber tracts of the connective nerves.

The presumptive ganglionic territory, bounded laterally by the deep longitudinal fibers, initially occupies somewhat less than half of the width of the germinal plate (Fig. $4 D$, bottom) and, on each side, corresponds to a region of the embryo occupied by the $n$ bandlet and about half of the width of the $o$ bandlet. Neuroblasts and glioblasts that are destined for the CNS 

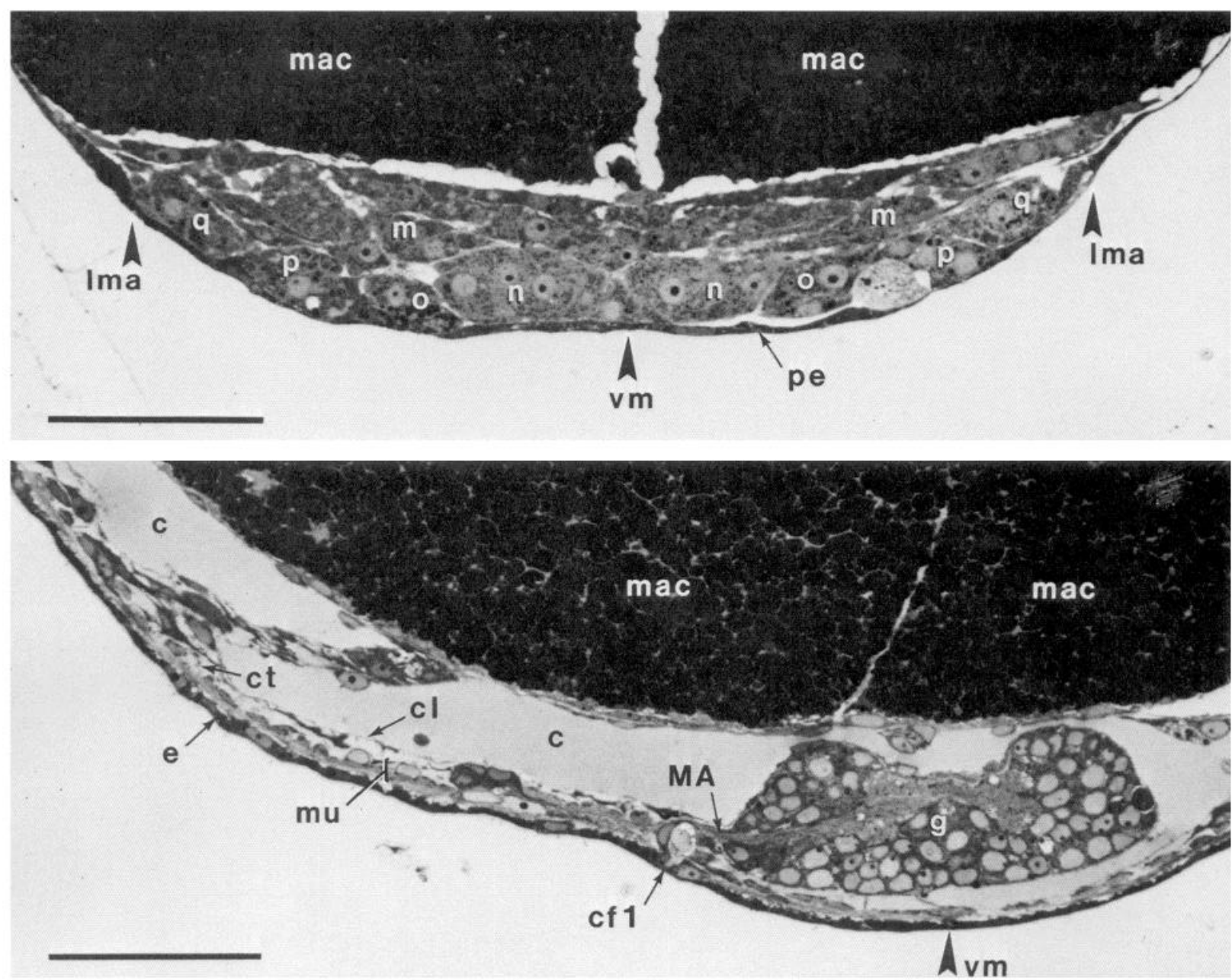

Figure 2. Transverse section of the germinal plate of an early stage 9 embryo, in a region where cell migration has not yet begun. The blast cells in each bandlet have divided several times, so that a transverse section through any given bandlet passes through more than 1 cell. A similar section is represented diagrammatically in Figure $1 \mathrm{~B}$. lma, lateral margin of the germinal plate; $m$, mesodermal bandlet; mac, macromere; $n, o, p$, and $q$, ectodermal bandlets; $p e$, provisional epidermis; $v m$, ventral midline. Bar, $50 \mu \mathrm{m}$.

Figure 3. Transverse section of the germinal plate of a stage 10 embryo, after completion of the cell migrations described in this paper. The ventral nerve cord and the major organs of the body wall are in place. The germinal plate is expanding to enclose the body; its lateral margins are beyond the field of view. $c$, coelom; $c f 1$, cell floret $1 ; c l$, coelomic lining epithelium; $c t$, connective tissue; $e$, epidermis; $g$, ganglion; $M A$, MA segmental nerve root; $m a c$, macromere; $m u$, circular and longitudinal muscle layers; $v m$, ventral midline. Bar, $50 \mu \mathrm{m}$.

and are derived from the $\mathrm{n}$ and $\mathrm{o}$ bandlets arise predominantly within the presumptive ganglionic territory and can be incorporated directly into the ganglionic rudiments, although they must undergo substantial rearrangement to achieve their final positions and may migrate short distances within the ganglionic rudiment. The p and q bandlets, however, initially lie completely outside the presumptive ganglionic territory (Figs. $7 A, 8$ ). Hence, neuroblasts and glioblasts that are destined for the CNS and are derived from the $\mathrm{p}$ and $\mathrm{q}$ bandlets must migrate mediad to enter the ganglionic rudiments.

\section{Kinship group patterns}

To facilitate the description of cell migration, it is useful to describe the distribution of cells in early stage 10, after the migration is complete. The term "kinship group" is used here to denote the set of cells in an anatomical segment that are derived from a given bandlet, and particular kinship groups are named according to their bandlet of origin. The members of each kinship group were identified by injecting the bandlet's precursor teloblast with a fluorescent cell lineage tracer. Such a tracer is passed on to all mitotic descendants of the injected teloblast, and to no other cells (Weisblat et al., 1980a). Thus, the distribution of cells derived from the injected teloblast's daughter bandlet was ascertained by examining the distribution of fluorescently labeled cells in stage 10 embryos.

The ectodermal kinship group patterns in early stage $10 \mathrm{em}$ bryos of $T$. rude are illustrated in Figures 5 and 6 . All cells are found on the same side of the embryo as their bandlet of origin, although many neurons have contralateral projections. These kinship group patterns are nearly identical to those previously described for $H$. triserialis and in the CNS of $H$. ghilianii (Kramer and Weisblat, 1985; Weisblat and Shankland, 1985; Weisblat et al., 1984), and the pattern elements in $T$. rude have been assigned the names of their apparent homologs in these other species. In the case of the 3 dopamine-containing peripheral neurons per hemisegment-cells MD, LD1, and LD2 (Blair, 1983; Stuart, 1981) - we have confirmed this homology by examining glyoxylic acid-induced dopamine fluorescence in embryos of $T$. rude (D. K. Stuart and S. A. Torrence, unpublished observations). Only one major pattern difference has been found between $T$. rude and either of the 2 other species: In the PNS a pair of neurons (oz2 and oz3; Fig. $5 C$ ) are present in the o kinship group pattern of $T$. rude, where $H$. triserialis has only one (oz2). Data are not yet available on this point for $\mathrm{H}$. ghi- 

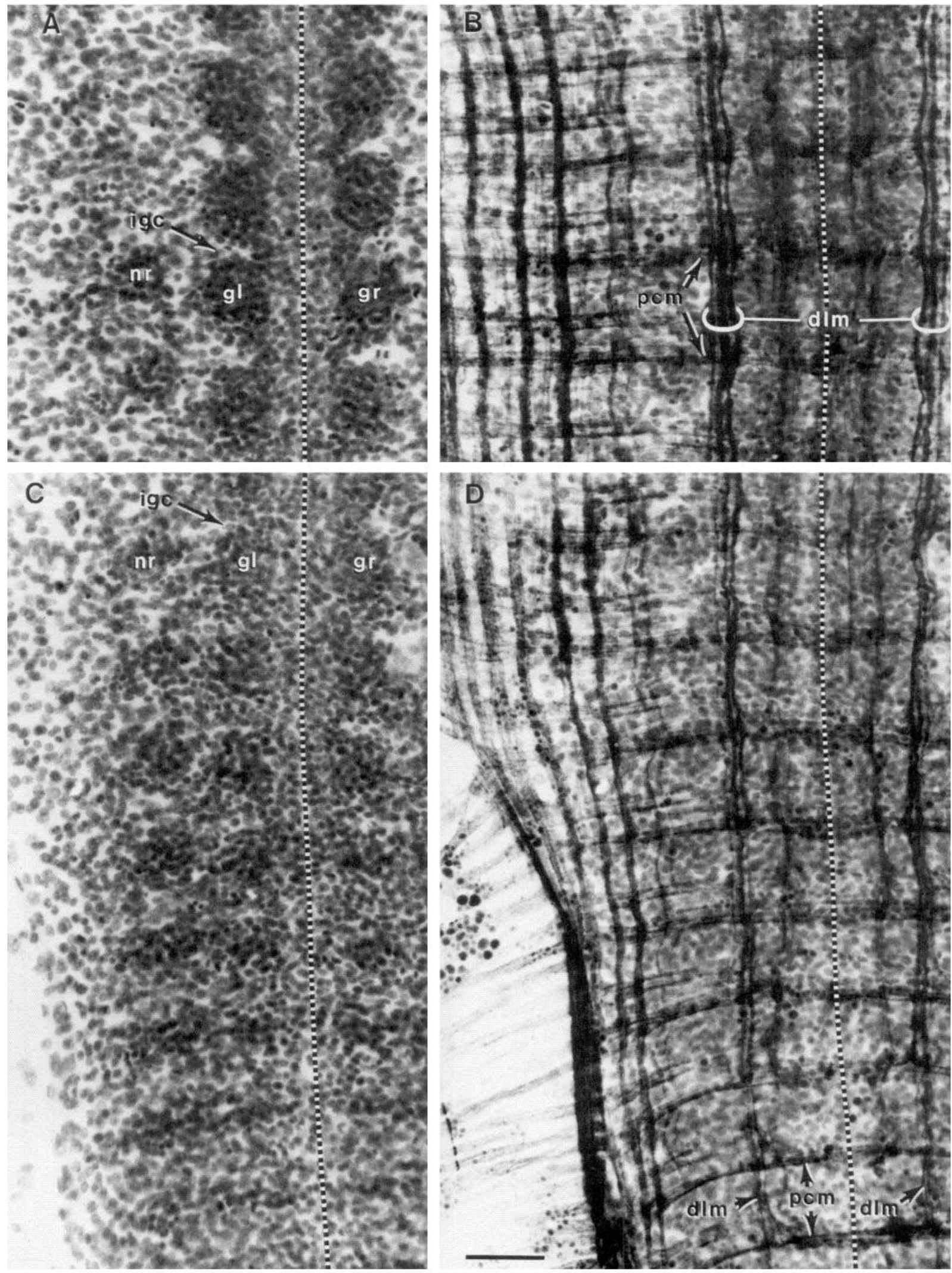

Figure 4. Relationship of body-wall muscles to ganglionic rudiments. Negative fluorescence micrographs of a whole-mounted stage 9 germinal plate, stained first with the DNA-specific Hoechst dye and then by indirect immunofluorescence with a monoclonal antibody directed against leech muscle fibers and a rhodamine-conjugated second antibody. Hoechst-stained cell nuclei appear as dark dots, and antibody-labeled muscle fibers appear as vertical and horizontal dark lines. Anterior is uppermost, and the ventral midline is indicated by a dotted line. $A$ and $C$, Single-exposure photomicrographs showing the distribution of cell nuclei. $B$ and $D$, Double-exposure photomicrographs showing both the antibody-labeled muscle fibers and the cell nuclei. $A$ and $B$ show the same field of view in segments X-XIII; $C$ and $D$ show the same field of view in the developmentally 
A

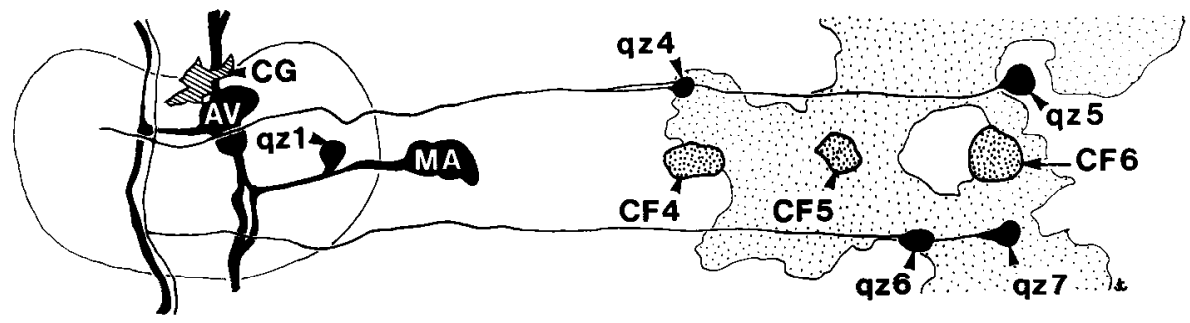

B

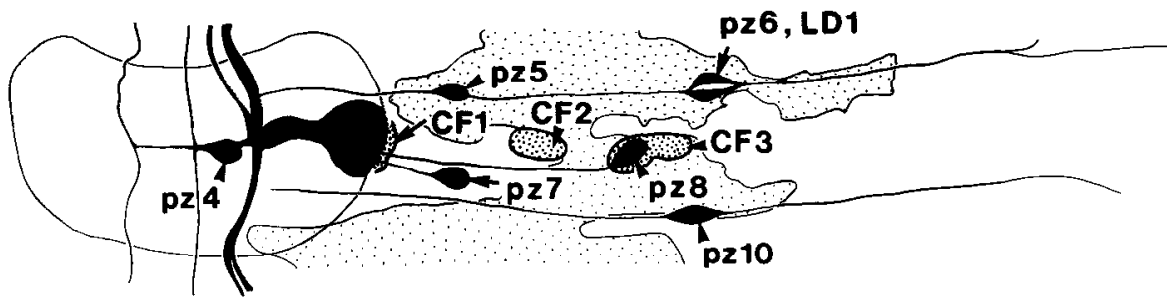

Figure 5. Diagram of ectodermal kinship group patterns in carly stage 10 embryos, traced from photomicrographs of RDA-labeled, wholemounted germinal plates. The right edge of the figure corresponds to the lateral margin of the expanding germinal plate, and thus to the future dorsal midline. Anterior is uppermost. Labeled neurites are shown, but no attempt has been made to render detailed projection patterns within the CNS; only major fiber tracts are shown. Labeled squamous epidermis is indicated by light stippling, epidermal cell florets $(C F)$, numbercd $1-6$, medial to lateral, are more densely stippled. Names of neurons (e.g., $q z l$ ) include a letter indicating kinship group membership (n, o, p, or q), a " $z$ " to symbolize the (unknown) intermediate cell lineage, and a number. LD1 and LD2 designate identified dopamine-containing neurons (Blair, 1983; Stuart, 1981). A, q kinship group. $A V$, Anteroventral, central neuron cluster; $C G$, connective glioblast; $M A$, peripheral neuron cluster along the MA nerve. $B$, p kinship group. $C$, o kinship group. $A D$, Anterodorsal, central neuron cluster; $P V$, posteroventral, central neuron cluster. $D$, n kinship group. Fine, labeled processes fill most of the contralateral neuropil (asterisk, outlined by dashed line). lianii. No instance has yet been found of an identified structure that belongs to different kinship groups in different species.

\section{The q pattern}

The $\mathrm{q}$ kinship group pattern includes 4 distinct elements in and near the ventral nerve cord that are derived from migratory cells (Figs. 5A, 6A). Those elements are (1) the glioblast of the ipsilateral interganglionic connective nerve, which is situated at the anterior margin of the ganglion, next to the ventral midline; (2) the AV cluster of neurons, which is situated anteroventrally within the ganglion; (3) the central neuron $\mathrm{qz} 1$, which is situated laterally in the ganglion, near the site of emergence of the MA segmental nerve root; and (4) the MA cluster of 6 or 7 peripheral neurons, which is situated along the path of the MA nerve a short distance from the lateral margin of the ganglion. The dopamine-containing neuron MD is one of the cells of the MA cluster.
The remaining elements of the $q$ kinship group pattern lie in the future dorsal body wall (Fig. $5 A$ ). They include 4 peripheral neurons (qz4 and qz5 situated along the AA nerve, and qz6 and qz7 situated along the PP nerve) and most of the epidermis of the future dorsal body surface, including both squamous common epidermal cells and a row of 3 clusters of cuboidal cells of unknown function, called cell florets (CF4, 5, and 6).

\section{The p pattern}

Within the ventral nerve cord the $\mathrm{p}$ kinship group pattern consists mainly of a wedge-shaped cluster of cells (Figs. $5 B, 6 B$ ). The medialmost 3 of these cells sometimes form a distinct cluster, separate from the larger main cluster; in position they correspond to neurons pz1, pz2, and pz3 of $H$. ghilianii (Kramer and Weisblat, 1985). In addition, there is a single ventromedial central neuron, designated $\mathrm{pz} 4$, which was found to be labeled in only about half of the ganglia of embryos in which the $p$

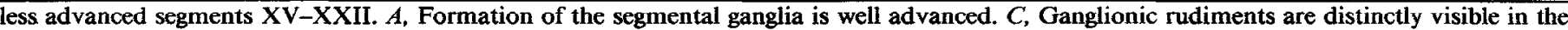
midbody segments at the top of the micrograph but not yet in the more posterior segments at the bottom of the micrograph. $B$ and $D$, Presumptive ganglionic territory is outlined by primary circular $(\mathrm{pcm})$ and deep longitudinal $(\mathrm{dlm})$ muscle fibers, even before the ganglionic rudiments become morphologically distinct. $d l m$, Deep longitudinal muscle fibers; $g l$ and $g r$, left and right sides of a single ganglionic rudiment; $i g c$, interganglionic cleft; $n r$, nephridial rudiment; $p c m$, primary circular muscle fibers. Bar, $50 \mu \mathrm{m}$. 

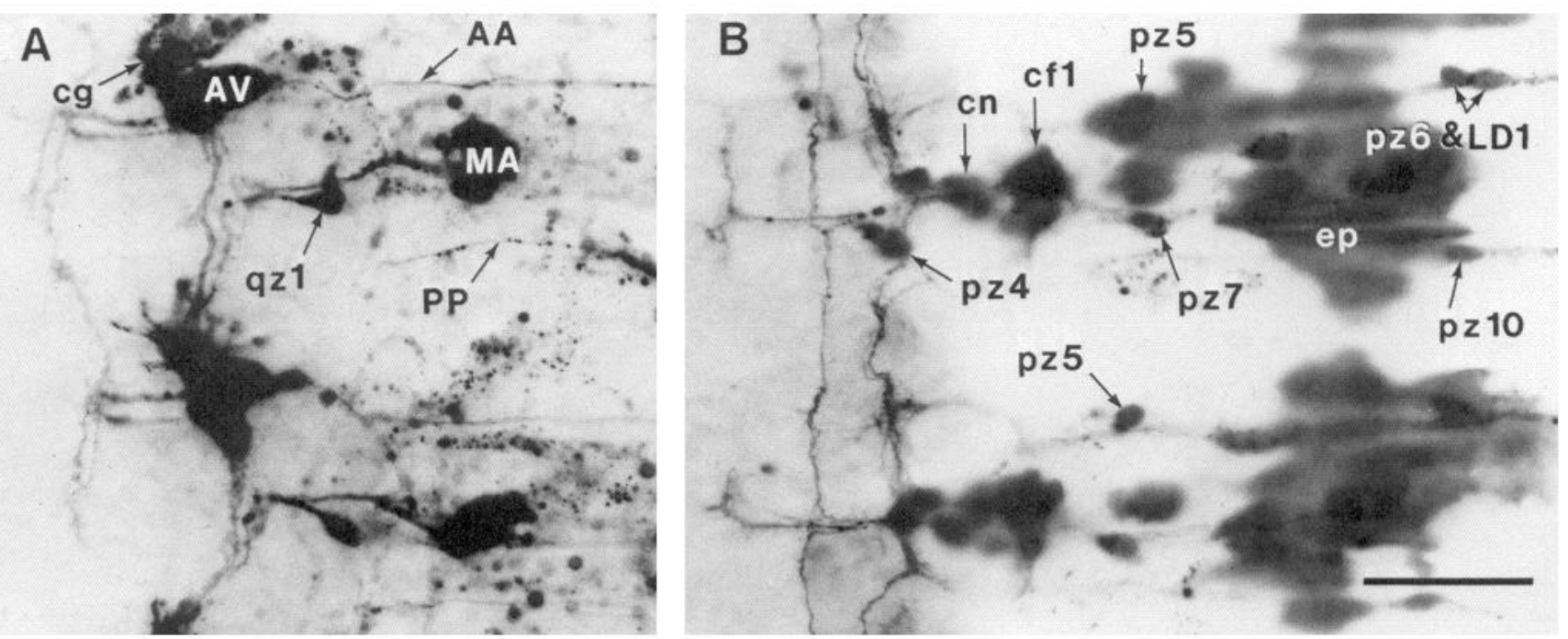

Figure 6. Ectodermal q and p kinship group patterns in and near the CNS ( $c f$. Fig. 5). Negative fluorescence images of whole-mounted, early stage 10 germinal plates. In each embryo the precursor teloblast of either the $\mathrm{q}$ or $\mathrm{p}$ bandlet had been injected with the fluorescent cell lineage tracer RDA. $A$, q kinship group pattern. Pattern elements in the future dorsal body wall are not shown here. $B$, p kinship group pattern. Neuron pz8 is obscured by overlying labeled epidermis in this micrograph. $A A$, Axons in the AA nerve; $c n$, central neurons; $e p$, epidermis; $P P$, axons in the PP nerve. Other abbreviations as in Figure 5. Bar, $50 \mu \mathrm{m}$.

bandlet had been labeled on only one side of the embryo. As in H. ghilianii (Kramer and Weisblat, 1985) and $H$. triserialis (Shankland and Weisblat, 1984), pz4 is probably an unpaired neuron that has an equal probability of arising from the left or from the right $\mathrm{p}$ bandlet in any given segment.

In the periphery, the $\mathrm{p}$ kinship group pattern (Figs. $5 B, 6 B$ ) includes several neurons (pz5, pz6, and LD1 situated along the AA nerve, pz7 and pz8 situated along the MA nerve, and pz10 situated along the PP nerve), a large, ventral patch of squamous epidermal cells, cell florets 1 and 3 , and half of cell floret 2 (which is the rudiment of the nephridiopore). Cell floret 1 (CF1; Figs. 3, $5 B, 6 B$ ) is situated at the margin of the ganglion, ventral to the site of emergence of the MA segmental nerve.

\section{Cell migration}

To follow the migration of cells from the $\mathrm{p}$ and $\mathrm{q}$ bandlets, the distribution pattern of lineage tracer-labeled cells belonging to either kinship group was examined in a series of segments of embryos at various developmental ages within stage 9 .

\section{Migrations from the $q$ bandlet}

Migratory cells first appear as a medially directed protrusion from the $\mathrm{q}$ bandlet (Fig. $7 A$ ). This protrusion initially consists of only 3 or 4 cells, which move mediad immediately posterior to the primary circular muscle fiber, along the path that will later be taken by the AA segmental nerve. The leading 2 cells separate from the trailing cells and quickly enter the ganglionic rudiment (Fig. 7A, hollow arrows). The more medial of these 2 leading cells settles at the intersection of the ventral midline and the anterior margin of the segment. This is the glioblast destined for the connective nerve. As adjacent ganglia move apart later in development, this cell will give rise to the glia of the ipsilateral connective nerve between its ganglion of origin and the next anterior ganglion. The more lateral of the 2 leading cells is a neuron that settles just lateral to the connective glioblast and immediately begins to extend ipsilateral neurites anteriorly and posteriorly in the forming longitudinal fiber tracts.

The trailing group of cells follows the same lateral-to-medial path but pauses in its migration at the anterolateral margin of the ganglionic rudiment (Fig. $7 A$, solid arrows). Here, the cells proliferate, as indicated by mitotic figures revealed by staining with the DNA-specific Hoechst dye. Most of the cells arising from this proliferation eventually move deep into the ganglionic rudiment. They settle near the neuron that arrived earlier and, together with that cell, constitute the AV cluster (Fig. 7B). However, a few of the cells apparently remain outside the ganglionic rudiment and move a short distance posteriad to contribute to the MA cluster of peripheral neurons.

Another small group, initially consisting of 2 or 3 cells, migrates mediad along a second, midsegmental path, roughly halfway between successive primary circular muscle fibers (Fig. $7 \mathrm{~A}$, arrowheads). This corresponds to the path later taken by the MA segmental nerve. These cells stop their migration when they reach the margin of the ganglionic rudiment, where they contribute to the MA cluster of peripheral neurons.

It is not yet known from which group of migratory cells the central neuron qz1 (Figs. 5A, 6A) is derived, but it enters the ganglion separately from the cells of the AV cluster. During the coalescence of the MA cluster, one of its more medial cells moves slightly apart from the rest of the cluster and grows a neurite medially into the ganglion. This cell is qzl (Fig. 7B).

When the germinal plate subsequently expands during stage 10 , the MA cluster gradually moves laterad, away from the nerve cord, leaving qzl behind at the margin of the ganglion. This laterad movement of the MA cluster is not a true migration, however, in that the neurons are not moving through or across

Figure 7. Migration of neural precursor cells from the q bandlet toward the CNS. Negative fluorescence images of whole-mounted germinal plates. The left (apparent right) q bandlet was labeled by injection of RDA into its precursor teloblast in stage 6 and the embryos were fixed early $(A)$ or late $(B)$ in stage 9 . In the embryo shown in $A$, muscle fibers were also stained by indirect immunofluorescence using a fluorescein-conjugated second antibody. Anterior is uppermost, and the approximate ventral midline is indicated by a dotted line. Curvature of the embryos is an artifact of the mounting process. A, Early events of migration. Double-exposure photomicrograph showing both the RDA-labeled, $\mathrm{q}$ bandlet-derived cells and 

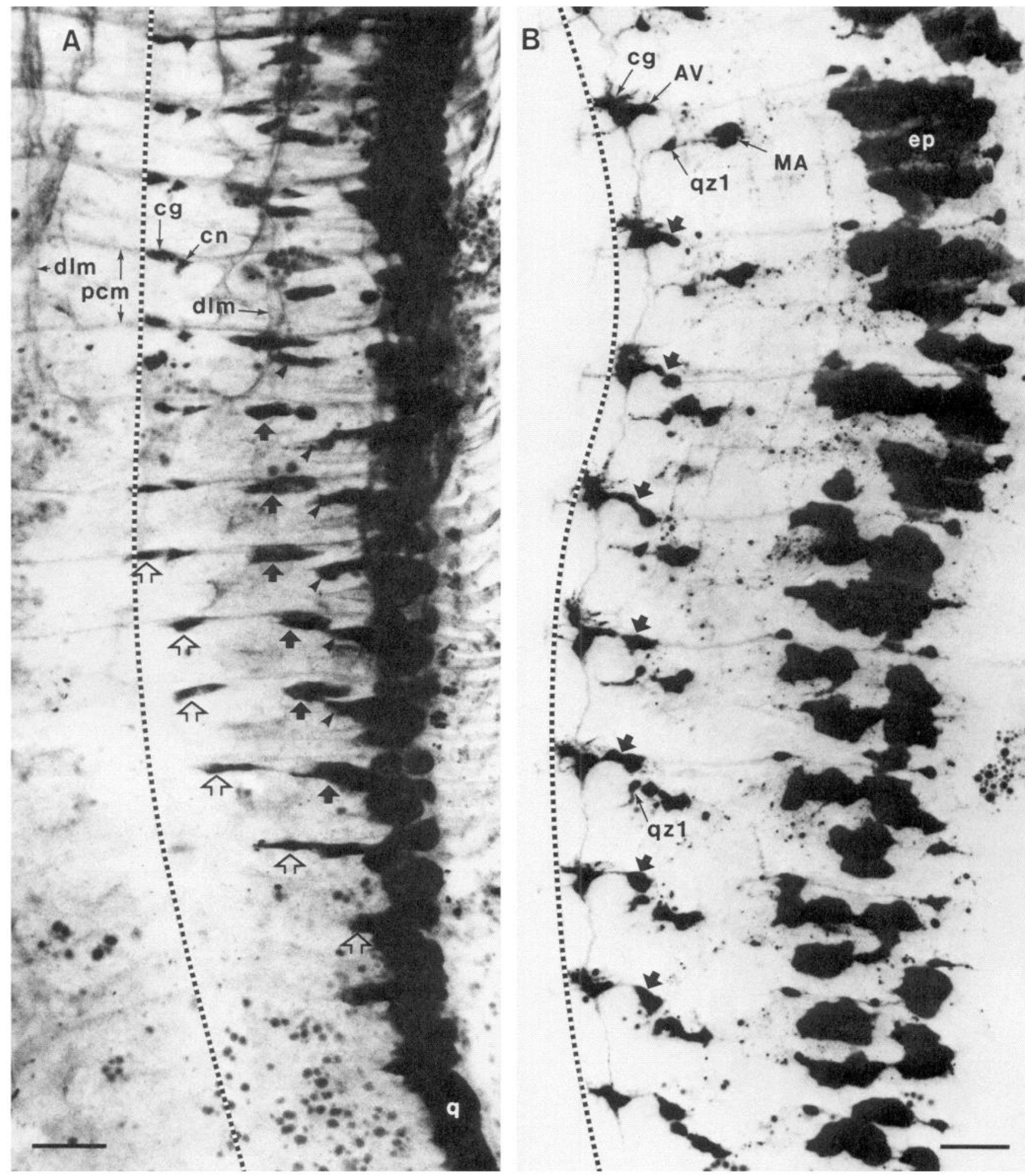

the antibody-labeled muscle fibers. The q bandlet $(q)$ occupies the lateral margin of the germinal plate. In the posteriormost (and least developed) of the approximately 16 segments shown, migration is just beginning, while in progressively more anterior segments, migration is progressively more advanced. From the initial mediad protrusion of cells from the $\mathrm{q}$ bandlet, 2 cells move quickly to the ventral midline (hollow arrows) along a path just posterior to the primary circular muscle fiber $(\mathrm{pcm})$. The more medial of these 2 becomes the connective glioblast $(\mathrm{cg})$, while the more lateral cell becomes a neuron ( $\mathrm{cn}$ ). Another group of cells (solid arrows) subsequently follows the same path to the margin of the ganglionic rudiment (marked by the deep longitudinal muscle fibers: $\mathrm{dlm}$ ), where they proliferate. Somewhat later, a third group of cells (arrowheads) moves to the edge of the ganglionic rudiment along a somewhat more posterior path. $B$, Late events of migration. Single-exposure photomicrograph showing RDAlabeled, q bandlet-derived cells. Arrows indicate cells moving from the proliferating cluster at the margin of the ganglionic rudiment into the AV cluster within the ganglion. Neuron qz1 arises from the forming MA cluster. $A V$, Anteroventral central neuron cluster; $c g$, connective glioblast; $c n$, central neuron; $d l m$, deep longitudinal muscle fibers; $e p$, epidermis; $M A$, peripheral neuron cluster along the MA nerve; $p c m$, primary circular muscle fibers; $q$, q bandlet. Bar, $50 \mu \mathrm{m}$. 


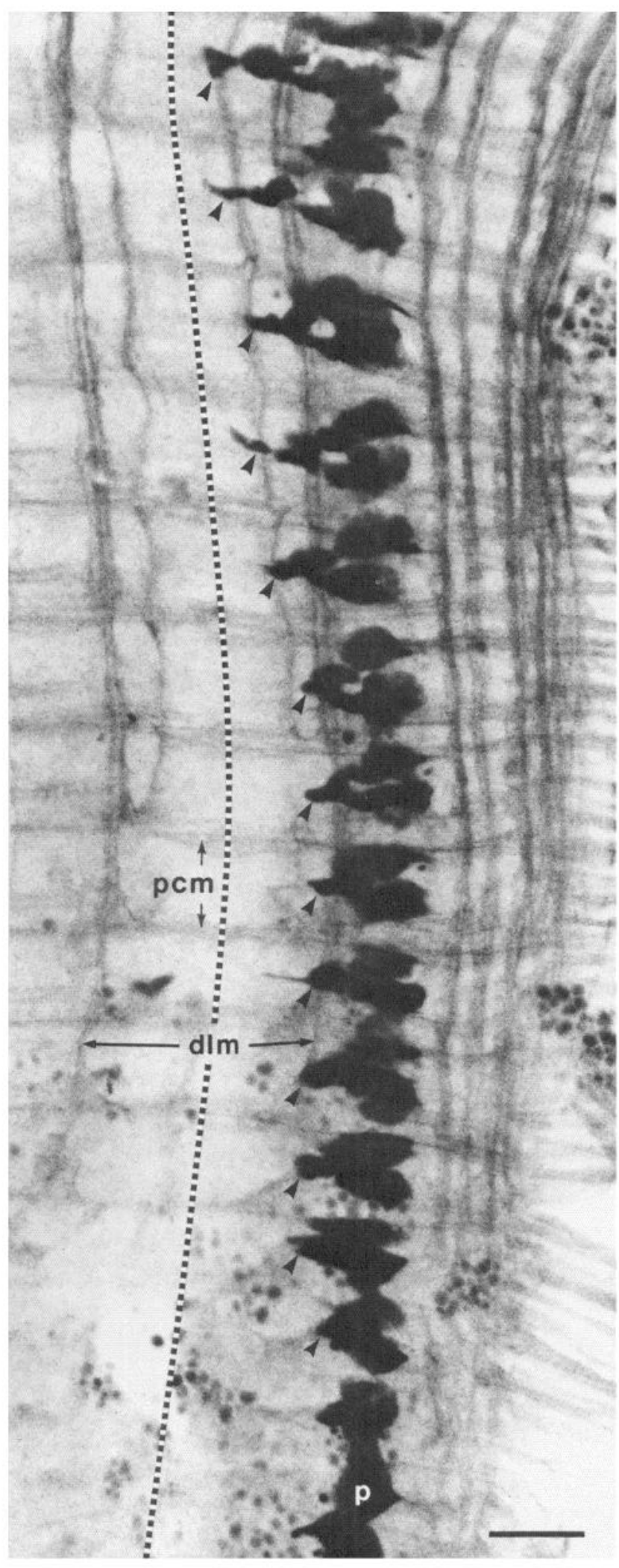

Figure 8. Migration of neural precursor cells from the $\mathrm{p}$ bandlet toward the CNS. The left (apparent right) $p$ bandlet $(p)$ was labeled by injection of RDA into its precursor teloblast in stage 6 , the embryo was fixed in early stage 9 , and the muscle fibers were stained by indirect immunofluorescence using a fluorescein-conjugated second antibody. This double-exposure photomicrograph shows a negative fluorescence image of the RDA-labeled, $p$ bandlet-derived cells superimposed on the anti- other tissues to acquire new neighbors. Rather, as the germinal plate expands, the neurons of the MA cluster maintain a consistent set of associations with cell floret 2 (the nephridiopore rudiment) and with adjacent muscle fibers of the body wall, and all of these structures move away from the midline in concert.

\section{Migration from the $p$ bandlet}

All of the precursors of the $\mathrm{p}$ kinship group pattern elements within the ventral nerve cord enter the presumptive ganglionic territory along a single midsegmental path, approximately halfway between successive primary circular muscle fibers (Fig. 8). These migratory cells first become visible as a medially directed protrusion from the $\mathrm{p}$ bandlet at about the same time that migratory q bandlet cells first protrude from their bandlet in the same segment. The protrusion from the $\mathrm{p}$ bandlet contains not only neural precursors destined to enter the ganglionic rudiment, but also cells destined to form cell floret 1 . The precursors of cell floret 1 stop their migration near the margin of the presumptive ganglionic territory, and many of the neural precursor cells must subsequently migrate past them to enter the ganglionic rudiment.

\section{Segmental differences}

Examination of embryos of various ages permits the sequence of developmental events to be observed in various body regions. Such experiments, whose results are not presented here in detail, were carried out for segments IV-XXII. This survey did not reveal any significant regional differences in the patterns of migration of neural precursors from the $\mathrm{q}$ or $\mathrm{p}$ bandlets toward the CNS.

\section{Discussion}

In embryos of the glossiphoniid leech $T$. rude, the neuroblasts and glioblasts that belong to the $\mathrm{p}$ and $\mathrm{q}$ ectodermal kinship groups and are destined for the CNS arise outside the presumptive ganglionic territory. Small groups of these cells migrate from their bandlet of origin along stereotyped pathways to reach their definitive locations in and near the ganglionic rudiment, and each group of migratory cells gives rise to a stereotyped set of elements in the kinship group pattern.

The stereotypy of the migration routes and of the final cell positioning suggests that mechanisms exist that constrain migrating cells to move along appropriate paths and ensure that the migration stops when appropriate destinations are reached. Tissue interactions are known to be required for normal morphogenesis of the leech CNS. Experiments with $H$. triserialis, in which formation of the entire ectoderm or mesoderm was prevented on one side of the embryos, have shown that neither the ectoderm nor the mesoderm is capable of undergoing normal segmental morphogenesis in the absence of the other germ layer (Blair, 1982). Similarly, ablation of the ectodermal $\mathrm{n}$ kinship group produced sporadic abnormalities in the contributions of the remaining ectodermal kinship groups to the ventral nerve cord in the affected segments (Blair and Weisblat, 1982).

body-labeled muscle fibers in approximately 15 segments of a wholemounted germinal plate. Anterior is uppermost, and the approximate ventral midline is indicated by a dotted line. In the posteriormost (and least developed) segments shown, migration is just beginning, while in progressively more anterior segments, migration is progressively more advanced. Migratory cells (arrowheads) appear in each segment as a medial protrusion from the $\mathrm{p}$ bandlet and then move mediad into the presumptive ganglionic territory outlined by the primary circular $(\mathrm{pcm})$ and deep longitudinal $(\mathrm{dlm})$ muscle fibers. At this magnification, cell floret 1 cannot be distinguished from the migratory neuroblasts. $\mathrm{dlm}$, Deep longitudinal muscle; $p$, $\mathrm{p}$ bandlet; $p c m$, primary circular muscle. Bar, $50 \mu \mathrm{m}$. 
A variety of cell types are present along the paths of the migrating neuroblasts and glioblasts, and thus might provide guidance or positional cues. Among these are muscle fibers, differentiating peripheral neurons, and prospective epidermal cells of at least 2 types. For example, the primary circular muscle fiber and peripheral neurons oz1, pz5, pz6, and LD1 are all situated along a circumferential line that corresponds to the anterior migratory path of $\mathrm{q}$ bandlet cells, while cell florets 1 , 2 , and 3 and peripheral neurons pz 7 and pz8 are situated along a midsegmental, circumferential line that corresponds to the midsegmental migration path. Selective ablations of cells situated along the migration paths should provide insight into whether interactions with such cells participate in the guidance of migration or the control of final cell position.

Previous ablation experiments also suggest that the responses of migratory neuroblasts and glioblasts to the hypothetical cues provided by surrounding tissues depend on the migratory cells' own identities. If the germinal bandlet that would have given rise to the p kinship group is ablated, the remaining bandlet, which would otherwise have given rise to the o kinship group, becomes "transfated" and gives rise instead to a pattern of descendant tissues typical of the p kinship group; the o kinship group is then missing (Shankland and Weisblat, 1984; Weisblat and Blair, 1984; Zackson, 1984). In order to take up the positions characteristically occupied by cells that migrate from the normal p bandlet, transfated cells must acquire not only the identities, but also the migratory properties and the hypothetical responses to positional cues that are characteristic of $p$ kinship group cells. The results of such transfating experiments also imply that guidance cues from cells of the o kinship group are not required for migration and normal final positioning of $p$ kinship group cells.

Migrations of neuroblasts and immature neurons play prominent roles in the development of both the CNS and PNS of vertebrates (Caviness et al., 1981; Le Douarin, 1982, 1984; Rakic, 1971, 1972; Rakic and Sidman, 1973). Cell migration has been accorded less prominence in descriptions of invertebrate neurogenesis, although it does play at least a minor role in several groups. In insect embryos, central neuroblasts arise in situ (Bate, 1976; Bate and Grunewald, 1981), but a few central neurons migrate from their birthplaces within the CNS to their definitive positions (Goodman et al., 1982, 1984; Taghert et al., 1982). Most peripheral sensory neurons in insects are also born in situ (Bate, 1978), but cell migration may be involved in some peripheral and postembryonic neurogenesis (Heathcote, 1981; Mouze, 1980). In the nematode Caenorhabditis elegans, some postembryonic neuroblasts migrate short distances from their ventrolateral birthplaces to enter the ventral nerve cord (Sulston and Horvitz, 1977), and a few embryonic and postembryonic neuroblasts and neurons undertake much longer longitudinal migrations (Sulston and Horvitz, 1977; Sulston et al., 1983).

Cell migrations similar to those described here for $T$. rude are a common feature of gangliogenesis in glossiphoniid leeches. Such migrations were first observed in $H$. triserialis (Stuart et al., 1982; Weisblat et al., 1984), where groups of cells corresponding to those of $T$. rude follow similar migration routes (Torrence, 1984, and unpublished observations). Migration of groups of cells that correspond to at least some of the migratory neural precursors from the $\mathrm{p}$ and $\mathrm{q}$ bandlets in $T$. rude has also been observed in $H$. ghilianii (Stuart et al., 1982; D. K. Stuart and D. A. Weisblat, unpublished observations).

Centripetal migrations of prospective central neuroblasts and glioblasts are not the only cell migrations that shape the leech nervous system: Some peripheral neurons also migrate centrifugally to reach their characteristic positions. For example, peripheral neurons $n z 1, n z 2$, and $n z 3$ arise within the presumptive ganglionic territory and must migrate laterad to reach the periphery (Weisblat et al., 1978), and several other peripheral neurons (pz6, pz10, LD2) arise near the lateral margin of the presumptive ganglionic territory and must also migrate to reach their more lateral definitive positions (Braun, 1985).

Despite the metamerically stereotyped architecture of the leech nervous system, significant regional differentiation of the adult leech nerve cord does exist. For example, the anteriormost 4 and posteriormost 7 segmental ganglia (belonging, respectively, to segments I-IV and XXVI-XXXII), which arise as distinct ganglionic rudiments in the embryo, are fused into compound subesophageal and caudal ganglia in the adult (Mann, 1962; Muller et al., 1981), and ganglia in the genital segments (IX, X) contain more neurons than the typical midbody ganglion (Macagno, 1980). In addition, some identified neurons are present only in specific subsets of the segmental ganglia (Muller et al., 1981). Such regional differences might arise early in development, possibly by regional modifications of the cell-lineage patterns that generate the neural tissues or of the migration patterns of neural precursors. Alternatively, the early development might be identical in all segments, with regional differences arising at later developmental stages.

The segments examined in this study (segments IV-XXII) include the genital segments (IX, X) and 1 of the 4 segments whose ganglia will fuse to form the subesophageal ganglion (IV), as well as segments that will contain "typical" midbody ganglia. No regional differences were observed in any aspect of cell migration studied here, although subtle differences, such as small differences in the number of migratory cells or in the numbers of their proliferative divisions en route, might have gone undetected. This finding supports the view that regional differences in the architecture of the leech CNS arise only after the initial condensation of the ganglionic rudiments. Stewart and Macagno (1984) have reached a similar conclusion on the basis of comparative cell counts in ganglia of genital and nongenital segments of the hirudid leech Haemopis marmorata. The earliest regional difference so far described among embryonic leech ganglia appears in the developing projection patterns of the Retzius neurons in the genital segments of Hirudo medicinalis, at the time when the newly formed ganglia are moving apart and the connective nerves are forming between them (Jellies et al., 1985; Loer et al., 1985; Mason et al., 1984). Thus, with respect to the late genesis of segmental differences, the embryonic development of the leech CNS may differ somewhat from that of grasshoppers, where some segment-specific differences appear at the earliest stages of neurogenesis (Doe and Goodman, 1985), although for the most part a stereotyped segmental complement of neural cells arises in each ganglion and is subsequently remodeled by segment-specific patterns of cell death and differentiation (Goodman, 1982).

\section{References}

Bate, C. M. (1976) Embryogenesis of an insect nervous system. I. A map of the thoracic and abdominal neuroblasts in Locusta migratoria. J. Embryol. Exp. Morphol. 35: 107-123.

Bate, C. M. (1978) Development of sensory systems in arthropods. In Handbook of Sensory Physiology, Vol. IX. Development of Sensory Systems, M. Jacobson, ed., pp. 1-53, Springer-Verlag, New York.

Bate, C. M., and E. B. Grunewald (1981) Embryogenesis of an insect nervous system. II. A second class of neuron precursor cells and the origin of the intersegmental connectives. J. Embryol. Exp. Morphol. 61: $317-330$

Blackshaw, S., J. G. Nicolls, and I. Parnas (1982) Physiological responses, receptive fields and terminal arborizations of nociceptive cells in the leech. J. Physiol. (Lond.) 326: 251-260.

Blair, S. S. (1982) Interactions between mesoderm and ectoderm in segment formation in the embryo of a glossiphoniid leech. Dev. Biol. 89: 389-396.

Blair, S. S. (1983) Blastomere ablation and the developmental origin of identified monoamine-containing neurons in the leech. Dev. Biol. 95: 65-72.

Blair, S. S., and D. A. Weisblat (1982) Ectodermal interactions during 
neurogenesis in the glossiphoniid leech Helobdella triserialis. Dev. Biol. 91: 64-72.

Braun, J. (1985) Cells that guide the growth of neuronal processes in the leech embryo. Ph.D. thesis, University of California, Berkeley.

Caviness, V. S., N. C. Pinto-Lord, and P. Evrard (1981) The development of laminated pattern in the mammalian neocortex. In Morphogenesis and Pattern Formation, T. G. Connelly, L. L. Brinkley, and B. M. Carlson, eds., pp. 103-126, Raven Press, New York.

Doe, C. Q., and C. S. Goodman (1985) Early events in insect neurogenesis. I. Development and segmental differences in the pattern of neuronal precursor cells. Dev. Biol. 111: 193-205.

Fernandez, J. (1980) Embryonic development of the glossiphoniid leech Theromyzon rude: Characterization of developmental stages. Dev. Biol. 76: 245-262.

Fermandez, J., and N. Olea (1982) Embryonic development of glossiphoniid leeches. In Developmental Biology of Freshwater Invertebrates, F. W. Harrison and R. R. Cowen, eds., pp. 317-361, Liss New York.

Fernandez, J., and G. S. Stent (1980) Embryonic development of the glossiphoniid leech Theromyzon rude: Structure and development of the germinal bands. Dev. Biol. 78: 407-434.

Giloh, H., and J. W. Sedat (1982) Fluorescence microscopy: Reduced photobleaching of rhodamine and fluorescein protein conjugates by $n$-propyl gallate. Science 217: 1252-1255.

Gimlich, R. L., and J. Braun (1985) Improved fluorescent compounds for tracing cell lineage. Dev. Biol. 109: 509-514.

Goodman, C.S. (1982) Embryonic development of identified neurons in the grasshopper. In Neuronal Development, N. C. Spitzer, ed., pp. 171-212, Plenum, New York, London.

Goodman, C. S., J. A. Raper, R. K. Ho, and S. Chang (1982) Pathfinding by neuronal growth cones during grasshopper embryogenesis. Symp. Soc. Dev. Biol. 40: 275-316.

Goodman, C. S., M. J. Bastiani, C. Q. Doe, S. du Lac, S. L. Helfand, J. Y. Kuwada, and J. B. Thomas (1984) Cell recognition during neuronal development. Science 225: 1271-1279.

Heathcote, R. D. (1981) Differentiation of an identified sensory neuron (SR) and associated structures (CTO) in grasshopper embryos. J. Comp Neurol. 202: 1-18.

Jellies, J., C. M. Loer, and W. B. Kristan, Jr. (1985) Morphogenesis of segment-specific innervation patterns in an identified leech neuron. Soc. Neurosci. Abstr. 11: 956.

Karnovsky, M. J. (1965) A formaldehyde-glutaraldehyde fixative of high osmolality for use in electron microscopy. J. Cell Biol. 27: 137A$138 \mathrm{~A}$

Kramer, A. P., and D. A. Weisblat (1985) Developmental neural kinship groups in the leech. J. Neurosci. 5: 388-407.

Kuwada, J. Y., and A. P. Kramer (1983) Formation of the receptive fields of leech mechanosensory neurons during embryonic development. J. Neurosci. 3: 2474-2486.

Le Douarin, N. M. (1982) The Neural Crest, Cambridge U.P., Cambridge, MA.

Le Douarin, N. M. (1984) Cell migrations in embryos. Cell 38: 353360

Loer, C. M., J. Jellies, and W. B. Kristan, Jr. (1985) The possible role of target interactions in the development of segment-specific differences of an identified neuron. Soc. Neurosci. Abstr. 11: 957.

Macagno, E. R. (1980) Number and distribution of neurons in leech segmental ganglia. J. Comp. Neurol. 190: 283-302.

Mann, K. H. (1953) The segmentation of leeches. Biol. Rev. 28: 115.

Mann, K. H. (1962) Leeches (Hirudinea), Pergamon Press, New York.

Mason, A. J. R., J. C. Glover, and W. B. Kristan, Jr. (1984) Embryonic development of segmentally specialised serotonergic neurones in the leech Hirudo medicinalis. Soc. Neurosci. Abstr. 10: 1033.

Mouze, M. (1980) Autoradiographic study of proliferation and cell migration during larval growth of the visual apparatus in Aeshna cyanea (Odonata: Aeshnidae). Int. J. Insect Morphol. Embryol. 9: 4152.

Muller, K. J., J. G. Nicholls, and G. S. Stent, eds. (1981) Neurobiology of the Leech, Cold Spring Harbor Laboratory, New York.

Rakic, P. (1971) Neuron-glial relationship during granule cell migra- tion in developing cerebellar cortex. A Golgi and electron microscopic study in Macacus rhesus. J. Comp. Neurol. 141: 283-312.

Rakic, P. (1972) Mode of cell migration to the superficial layers of the fetal monkey neocortex. J. Comp. Neurol. 145: 61-84.

Rakic, P., and R. L. Sidman (1973) Weaver mutant mouse cerebellum: Defective neuronal migration secondary to abnormality of Bergmann glia. Proc. Nat. Acad. Sci. USA 70: 240-244.

Rude, S. (1969) Monoamine-containing neurons in the central nervous system and peripheral nerves of the leech Hirudo medicinalis. J. Comp. Neurol. 136: 349-371.

Shankland, M., and D. A. Weisblat (1984) Stepwise commitment of blast cell fates during the positional specification of the $\mathrm{O}$ and $\mathrm{P}$ cell lines in the leech embryo. Dev. Biol. 106: 326-342.

Stent, G. S. (1985) The role of cell lineage in development. Phil. Trans. R. Soc. Lond. [Biol.] 312: 3-19.

Stent, G. S., D. A. Weisblat, S. S. Blair, and S. L. Zackson (1982) Cell lineage in the development of the leech nervous system. In Neuronal Development, N. Spitzer (ed.), pp. 1-44, Plenum, New York.

Stent, G. S., D. A. Weisblat, and W. B. Kristan, Jr. (in press) Development of the leech nervous system. In Handbook of Physiology (Developmental Neurobiology), W. M. Cowan and V. B. Mountcastle eds., American Physiological Society, Bethesda, MD.

Stewart, R. R., and E. R. Macagno (1984) The development of segmental differences in cell number in the CNS of the leech. Soc. Neurosci. Abstr. 10:512.

Stuart, D. K. (1981) Monoamine neurons in embryonic and adult leech. Soc. Neurosci. Abstr. 7: 42.

Stuart, D. K., S. S. Blair, and D. A. Weisblat (1986) Cell lineage, cell death and the developmental origin of identified serotonin and dopamine neurons in the leech. J. Neurosci. (in press).

Stuart, D. K., I. Thomson, D. A. Weisblat, and A. P. Kramer (1982) Antibody staining of embryonic leech muscle, blast cell migration and neuronal pathway formation. Soc. Neurosci. Abstr. 8: 15.

Sulston, J. E., and H. R. Horvitz (1977) Post-embryonic cell lineages of the nematode, Caenorhabditis elegans. Dev. Biol. 56: 110-156.

Sulston, J. E., E. Schierenberg, J. G. White, and J. N. Thomson (1983) The embryonic cell lineage of the nematode Caenorhabditis elegans. Dev, Biol. 100: 64-119.

Taghert, P. H., M. J. Bastiani, R. K. Ho, and C. S. Goodman (1982) Guidance of pioneer growth cones: Filopodial contacts and coupling revealed with an antibody to Lucifer yellow. Dev. Biol. 94: 391-399.

Torrence, S. A. (1984) Neuroblast migration in leech embryos. Soc. Neurosci. Abstr. 10: 512 .

Torrence, S. A., and R. A. Cloney (1981) Rhythmic contractions of the ampullar epidermis during metamorphosis of the ascidian $\mathrm{Mol}$ gula occidentalis. Cell Tissue Res. 216: 293-312.

Weisblat, D. A. (1981) Development of the nervous system. In Neurobiology of the Leech, K. J. Muller, J. G. Nicholls, and G. S. Stent, eds., pp. 173-195, Cold Spring Harbor Laboratory, New York.

Weisblat, D. A., and S. S. Blair (1984) Developmental interdeterminacy in embryos of the leech Helobdella triserialis. Dev. Biol. 101: 326-335.

Weisblat, D. A., and M. Shankland (1985) Cell lineage and segmentation in the leech. Phil. Trans. R. Soc. Lond. [Biol.] 312: 39-56.

Weisblat, D. A., R. T. Sawyer, and G. S. Stent (1978) Cell lineage analysis by intracellular injection of a tracer enzyme. Science 202 . 1295-1298.

Weisblat, D. A., G. Harper, G. S. Stent, and R. T. Sawyer (1980a) Embryonic cell lineages in the nervous system of the glossiphoniid leech Helobdella triserialis. Dev. Biol. 76: 58-78.

Weisblat, D. A., S. L. Zackson, S. S. Blair, and J. D. Young (1980b) Cell lineage analysis by intracellular injection of fluorescent tracers. Science 209: 1538-1541.

Weisblat, D. A., S. Y. Kim, and G. S. Stent (1984) Embryonic origins of cells in the leech Helobdella triserialis. Dev. Biol. 104: 65-85.

Zackson, S. L. (1984) Cell lineage, cell-cell interaction, and segment formation in the ectoderm of a glossiphoniid leech embryo. Dev. Biol. 104: $143-160$

Zipser, B., and R. McKay (1981) Monoclonal antibodies distinguish identifiable neurons in the leech. Nature 289: 549-554. 